\title{
TGF- $\beta 1$ induces PGP9.5 expression in CAFs to promote the growth of colorectal cancer cells
}

\author{
WEI WEN ${ }^{1}, \mathrm{GE} \mathrm{LIU}^{2}, \mathrm{KE} \mathrm{JIN}^{3}$ and XIANG HU ${ }^{4}$ \\ ${ }^{1}$ Medical Department, ${ }^{2}$ Department of Anorectal Surgery, ${ }^{3}$ Emergency Department and ${ }^{4}$ Gastrointestinal Surgery, \\ The First Affiliated Hospital of Dalian Medical University, Dalian, Liaoning 116011, P.R. China
}

Received May 17, 2016; Accepted June 25, 2016

DOI: $10.3892 /$ or.2016.5238

\begin{abstract}
Numerous studies indicate that the interaction between cancer-associated fibroblasts (CAFs) and tumors is manifested in the entire process of colorectal cancer (CRC) cell development, in which TGF- $\beta 1$ plays a key role and has a significant effect on promoting the activation of CAFs. However, there are few studies on the mechanisms involved in the activation of CAFs by TGF- $\beta 1$ to produce an influence on tumor cells. TGF- $\beta 1$ was added to CAFs for further culture, and the expression of $\alpha$-SMA was significantly enhanced as shown by immunofluorescence assay. Western blot analysis was performed, and the results showed that TGF- $\beta 1$ promoted expression of PGP9.5 in a time-dependent manner. After siRNA was used to inhibit the expression of Smad2 or Smad3, the TGF- $\beta 1$-induced PGP9.5 expression in CAFs was obviously suppressed. In addition, TGF- $\beta 1$ was also found to promote the expression of PGP9.5 through the ERK1/2 and PI3K pathways. CAFs were cultured on the upper layer of a Transwell plate and TGF- $\beta 1$ was added. Simultaneously, CRC cells were cultured on the lower layer. The biological behaviors of the cancer cells were detected. According to the results, TGF- $\beta 1$ promoted the proliferation and invasion of CRC cells and inhibited their apoptosis while activating CAFs. This effect was achieved by induction of the expression of PGP9.5. However, when PGP9.5 was inhibited, the impact of TGF- $\beta 1$ on tumor cells after activation of CAFs was not fully blocked. Therefore, TGF- $\beta 1$ can promote PGP9.5 expression in CAFs to facilitate the growth of cancer cells. This finding aids in the identification of new targets for treating CRC.
\end{abstract}

\section{Introduction}

Colorectal cancer (CRC) is the third most common tumor worldwide only after lung and breast cancer. From a global

Correspondence to: Professor Xiang $\mathrm{Hu}$, Gastrointestinal Surgery, The First Affiliated Hospital of Dalian Medical University, 222 Zhongshan Road, Xigang, Dalian, Liaoning 116011, P.R. China E-mail:w11.5@163.com

Key words: TGF- $\beta 1$, cancer-associated fibroblasts, colorectal cancer, PGP9.5, Smad, ERK1/2, PI3K perspective, the incidence of CRC among malignant tumors ranks third in men, and second in women (1). In recent years, this incidence is rising. Therefore, in-depth research on the pathogenesis of CRC is of important realistic significance in improving the diagnosis and treatment efficacy of CRC and evaluation of the prognosis.

In the last century, investigations of CRC have focused on the tumor cells themselves, and the gene and epigenetic changes causing the occurrence and development of tumors have been widely accepted. However, increasing evidence suggests that the tumor microenvironment plays an important role in tumorigenesis, tumor infiltration and metastasis $(2,3)$. Cancer-associated fibroblasts (CAFs) in CRC tissues are the major cells of the tumor microenvironment and are closely related to the occurrence and development of CRC (4). CRC cells produce transforming growth factor (TGF)- $\beta$, epidermal growth factor (EGF), platelet-derived growth factor (PDGF) and other vital cytokines through paracrine mechanisms to induce activation of CAFs $(5,6)$. Activated CAFs can upregulate matrix metalloproteinases (MMPs) and plasminogen activator inhibitor (PAI)-1, ultimately playing a role in breaking through the basilar membrane, the invasion and metastasis of tumor cells $(7,8)$. According to experiments, CRC cells co-cultured with CAFs obviously became spindle-shaped to increase the metastasis capacity. Meanwhile, CAFs secrete MMPs to specifically degrade the extracellular matrix (ECM), preparing for cancer cell migration (9). Through 3-dimensional co-culture of tumor cells and CAFs, Brentnall (10) found that CAFs can prompt cancer cells to form pseudopodia and help them break through the basilar membrane. All these findings indicate that CAFs can directly increase the invasion ability of tumor cells and promote metastasis, and CAFs are directly involved in the developmental process of CRC.

The interaction between CAFs and tumor cells involves many signaling pathways, such as TGF- $\beta$, PDGF, SDF-1/CXCR4 and hepatocyte growth factor (HGF), of which TGF- $\beta$ has a critical role (11). TGF- $\beta$ can first induce fibroblast activation, and these activated fibroblasts promote the malignant transformation of epithelial cells (12). For example, according to a study by Kuperwasser et al (13), mammary stromal fibroblasts in mice overexpressing TGF- $\beta$ and/or HGF may induce human mammary epithelial cell cancerization, further developing into ductal breast cancer. Activated fibroblasts have been confirmed to promote tumor cell growth, 
while normal fibroblasts inhibit tumor cell growth. This is achieved mainly by secreting various factors or changing ECM components and accelerating epithelial cell cancerization (14), yet the specific mechanism remains unclear.

Studies have shown that TGF- $\beta$ can induce CAFs to express protein gene product (PGP9.5). In addition, PGP9.5 is a ubiquitin hydrolase, also known as ubiquitin $\mathrm{C}$ terminal hydrolase-L1 (UCH-L1). It regulates cellular processes in the cell hydrolysis pathway including cell cycle division and cell death (15). Current relevant research indicates a high expression of PGP9.5 in many tumors including CRC, medullary thyroid carcinoma, pancreatic, esophageal and bladder cancer $(15,16)$. In a previous study, in tumor tissues, PGP9.5 induced an increase in cyclin ubiquitination resulting in uncontrolled growth of undifferentiated cells, which is one of the key factors leading to oncogene activation (17). Through analysis of patients with ulcerative colitis, PGP9.5 was demonstrated to have a key function in the malignant transformation process from ulcerative colitis to carcinoma (18). In CRC, UCH-L1 hypomethylation was found to be closely associated with lymphatic metastasis, and in CRC patients with lymphatic metastasis, the methylation status of UCH-L1 was significantly reduced (19).

As found in the present study, TGF- $\beta$ induced PGP9.5 expression in CAFs to influence $\mathrm{CRC}$, which may be an important mechanism of the interaction between CAFs and tumor cells. Accordingly, the present study investigated the possible mechanisms of this interaction, thus contributing to a better understanding of the tumor growth environment, and the findings may aid in the identification of new targets for cancer therapy.

\section{Materials and methods}

Cell culture. CAFs were obtained from surgically resected CRC tissues at The First Affiliated Hospital of Dalian Medical University, Dalian, China. The present study was approved by the Ethics Committee of the National Cancer Center, China. The tissue was minced into 2- to 3-mm fragments and seeded into Dulbecco's modified Eagle's medium (DMEM) containing $10 \%$ fetal bovine serum (FBS) (both from Gibco-BRL, Carlsbad, CA, USA) and penicillin/streptomycin (Invitrogen, Carlsbad, CA, USA) (20). Specifically, the procedure, which is based on the selective growth advantage of fibroblasts under the culture conditions used, allowed for a $100 \%$ pure fibroblast population, as confirmed by positive staining for $\alpha$-SMA (Abcam, Shanghai, China). The fibroblast cultures were used until passage 10 .

Human CRC cell lines LoVo and HCT116 were obtained from the American Type Culture Collection (www.ATCC.org) and cultured in high-glucose DMEM containing $10 \%$ FBS. The cells were maintained at $37^{\circ} \mathrm{C}$ in an atmosphere of humidified air with $5 \% \mathrm{CO}_{2}$ in a cell culture incubator.

Immunofluorescence. CAFs were digested by $0.25 \%$ EDTAtrypsin (Invitrogen) and seeded at a density of $1 \times 10^{6}$ cells/well in 6-well plates treated with poly-L-lysine coverslips, and then TGF- $\beta 1$ ( 8 ng/ml; R\&D Systems, Minneapolis, MN, USA) was added. After $48 \mathrm{~h}$ the cells were fixed with $4 \%$ paraformaldehyde and then incubated in $1 \mathrm{ml}$ primary antibody ( $\alpha$-SMA) at $4^{\circ} \mathrm{C}$ overnight. After the addition of secondary antibody, the cells were washed with phosphate-buffered saline (PBS), treated with alcohol and xylene for gradient and transparence and were mounted with $10 \%$ glycerol phosphate. They were then placed under a fluorescence microscope camera for immunofluorescence detection.

Overexpression vector construction and transfection. RNA was extracted from LoVo cells using TRIzol (Invitrogen) according to the manufacturer's instructions, followed by reverse transcription PCR to amplify the coding region of TGF- $\beta 1$. In addition, the primers were TGF- $\beta 1-F$ (5'-ccc AAGCTTgecaccATGCCGCCCTCCGGGCTG-3') and TGF- $\beta 1-R$ ( 5 '-ccggaattcTCAGCTGCACTTGCAGGAGC GCA-3'). Then, the products were digested with HindIII and EcoRI (Takara, Dalian, China), cloned into pcDNA3.1 vectors, sequenced and verified. The cells were seed into a 6 -well plate at $1 \times 10^{5}$ cells $/ \mathrm{ml}$ and incubated for $24 \mathrm{~h}$. Transfection was carried out using Lipofectamine 2000 (Invitrogen) according to the manufacturer's instructions, when the cell confluence reached $\sim 70 \%$. The concentrations of plasmid and siRNAs for transfection were $4 \mu \mathrm{g} /$ well and $50 \mathrm{nM} /$ well. The sequence of the sense oligo for the siRNA directed against TGF- $\beta 1$ was, 5'-GGG CUA CCA UGC CAA CUU CTT-3'; for Smad2, 5'-GUC CCA UGA AAA GAC UUA ATT-3'; and for Smad3, 5'-GGA GAA AUG GUG CGA GAA GTT-3'. After transfection, TGF- $\beta 1$ and LY2109761 (10 $\mu \mathrm{mol} / 1$; Calbiochem, China) were added or not respectively, and then PD98059 (ERK1/2 inhibitor), LY294002 (PI3K inhibitor), SB203580 (p38 inhibitor) and SP600125 (JNK inhibitor) (all purchased from Calbiochem) were added respectively at a final concentration of $20 \mu \mathrm{M}$.

Western blot analysis. Total cellular proteins were extracted by incubating cells in lysis buffer (1X PBS, 1\% NP-40, 0.1\% SDS, $5 \mathrm{mM}$ EDTA, $0.5 \%$ sodium deoxycholate and $1 \mathrm{mM}$ sodium with protease inhibitors). The protein concentrations in the cell lysates were determined by bicinchoninic acid assay (Pierce, Rockford, IL, USA). SDS-PAGE was carried out on $8 \%$ glycine gels (Bio-Rad, Hercules, CA, USA) loading equal amount of proteins/lane. After electrophoresis, the separated proteins were transferred to a nitrocellulose membrane (Pierce) and blocked with 5\% non-fat milk in Tris-buffered saline with Tween-20 (TBST) buffer for $1 \mathrm{~h}$. After that, the membranes were incubated with PGP9.5, Smad2, Smad3 and $\beta$-actin antibodies (Cell Signaling Technology, USA) at 1:1000 dilutions in $5 \%$ non-fat milk overnight at $4^{\circ} \mathrm{C}$, and then anti-rabbit IgG monoclonal antibody conjugated with horseradish peroxidase (Cell Signaling Technology, Danvers, MA, USA) at 1:2,000 dilution for $1 \mathrm{~h}$ at room temperature. Protein bands were detected using the West Femto system (Pierce).

Cell proliferation. Cell proliferation was estimated in 96-well plates using a colorimetric immunoassay, based on the measurement of BrdU incorporation during DNA synthesis (BrdU ELISA kit; Roche Diagnostics, Mannheim, Germany). PGP9.5 siRNA was transfected and TGF- $\beta 1$ was added or TGF- $\beta 1$ and UCH-L1 (PGP9.5) inhibitor ( $5 \mu \mathrm{M}$; Calbiochem) were added at the same time. After cells were cultured for $48 \mathrm{~h}$, the medium was removed and cells were labeled with 
A
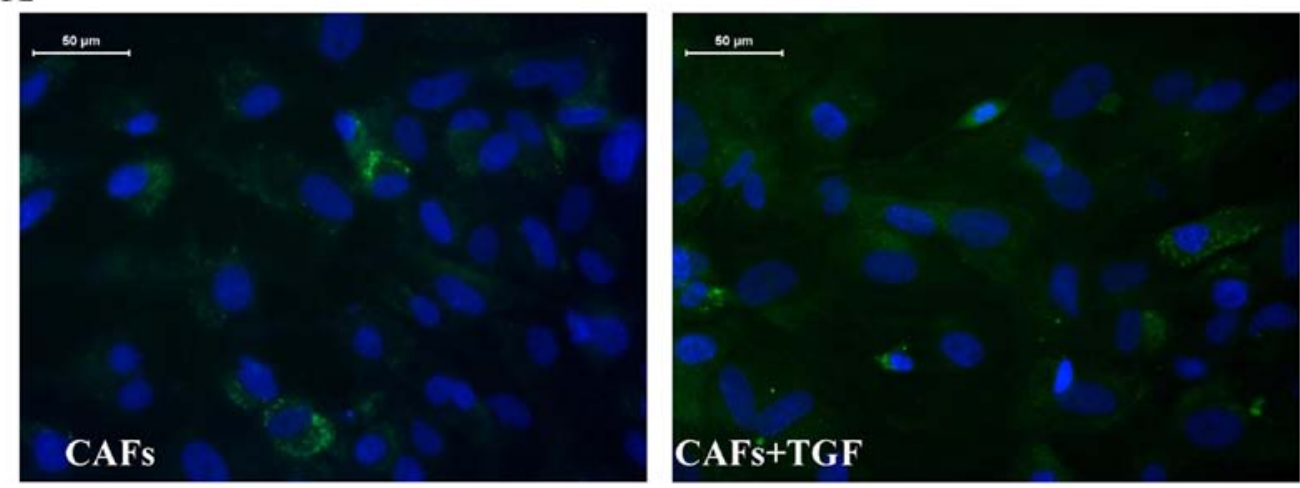

B

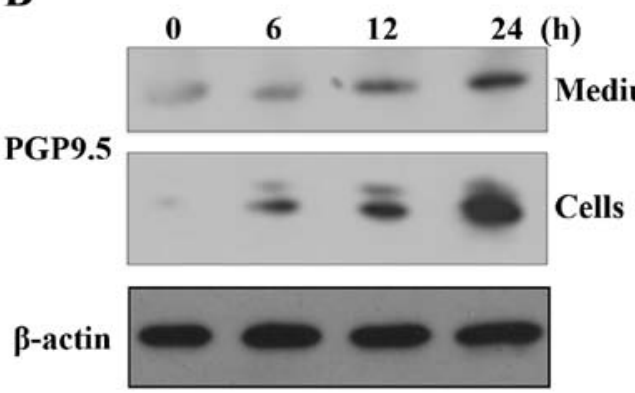

$\mathrm{C}$

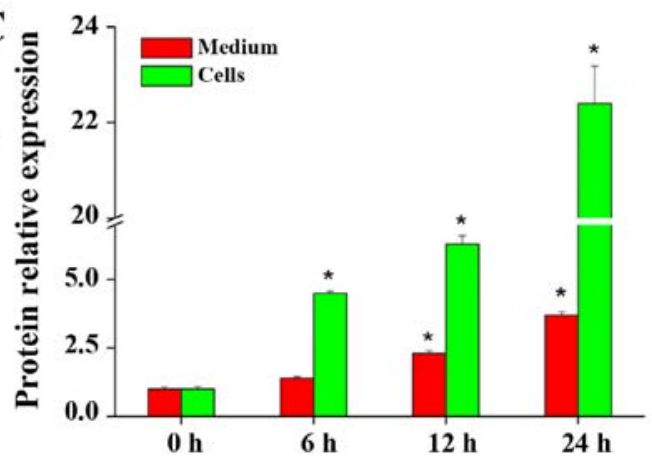

Figure 1. TGF- $\beta 1$ induces CAF activation and promotes PGP9.5 expression. (A) After addition of TGF- $\beta 1$ and culture for 48 h, $\alpha$-SMA expression was detected in CAFs by immunofluorescence assay. (B and C) After TGF- $\beta 1$ addition, western blotting was used to detect PGP9.5 expression in CAFs and medium at different time points. Each bar represents the mean \pm SD from three samples $\left({ }^{*} \mathrm{P}<0.01\right)$.

BrdU (10 mM 5-bromo-2'-deoxyuridine) for $3 \mathrm{~h}$ at $37^{\circ} \mathrm{C}$. Cells were fixed, and incubated with peroxidase-conjugated anti-BrdU antibody for $90 \mathrm{~min}$ at room temperature. Then, the peroxidase substrate 3,3',5,5'-tetramethylbenzidine was added, and BrdU incorporation was quantitated by differences in absorbance at wavelength 370 minus $492 \mathrm{~nm}$. Cell proliferation was expressed as the mean percentage of the control values (set at 100\%).

Cell cycle analysis. Cells were pelleted (400 x $\mathrm{g}$ for $5 \mathrm{~min}$ at $4^{\circ} \mathrm{C}$ ), washed twice with cold PBS, resuspended in $500 \mu \mathrm{l}$ of cold PBS, and then fixed for $1 \mathrm{~h}$ at $4^{\circ} \mathrm{C}$ by adding $500 \mu \mathrm{l}$ of fixation solution ( $2 \% \mathrm{w} / \mathrm{v}$ paraformaldehyde in PBS, $\mathrm{pH} 7.2)$. The fixed cells were pelleted, washed with cold PBS, resuspended in $1 \mathrm{ml}$ of $70 \%$ ethanol added dropwise to the pellet while vortexing and then incubated overnight at $4^{\circ} \mathrm{C}$. The next day, cells were pelleted and resuspended in $1 \mathrm{ml}$ propidium iodide solution ( $40 \mu \mathrm{g} / \mathrm{ml}$ with $100 \mu \mathrm{g} / \mathrm{ml} \mathrm{RNase} \mathrm{A)} \mathrm{for} 30 \mathrm{~min}$ at $37^{\circ} \mathrm{C}$ in the dark and analyzed on a FACScan flow cytometer (BD Biosciences, San Jose, CA, USA).

Transwell Matrigel invasion assay. Invasion of cells was evaluated by Transwell Matrigel invasion assay (BD, China). Briefly, $200 \mu \mathrm{l}$ of cells after transfection $\left(1 \times 10^{6}\right.$ cells $\left./ \mathrm{ml}\right)$ and $600 \mu \mathrm{l}$ of the complete medium was added to the upper and lower compartments of the chamber, respectively. After an incubation of $48 \mathrm{~h}$, cells that migrated to the lower side of the filter were fixed with $4 \%$ paraformaldehyde for $15 \mathrm{~min}$ at room temperature, washed with PBS, stained with crystal violet, and then observed under an inverted microscope (Olympus CKX41).
Statistical analyses. Experiments were carried out at least in triplicate and the results are expressed as mean \pm SD. Statistical analysis was performed using SPSS statistical program version 17 (SPSS, Inc., Chicago, IL, USA). Differences with a probability value $(\mathrm{P})<0.01$ were considered statistically significant.

\section{Results}

TGF- $\beta 1$ induces CAF activation while promoting PGP9.5 expression simultaneously. CAFs were isolated from surgically resected CRC tissues, and an immunofluorescence assay was used to determine the expression of $\alpha$-SMA. The results showed that $\alpha$-SMA expression was significantly increased when TGF- $\beta 1$ was added (Fig. 1A). An increase in $\alpha$-SMA expression is indicative of fibroblast activation. This showed that TGF- $\beta 1$ promoted activation of CAFs in CRC. PGP9.5 expression was also detected (Fig. 1B and C). With the prolonged duration of TGF- $\beta 1$ stimulation, the expression of PGP9.5 was gradually increased and the difference was significant. However, PGP9.5 in the cells and media showed a consistent increased expression trend. According to further validation of the above mentioned results, PGP9.5 expression was obviously reduced after adding siRNA specifically targeting TGF- $\beta 1$ or its inhibitor LY2109761. When the TGF- $\beta 1$ overexpression vector was transfected, the effect was similar to that after directly adding TGF- $\beta 1$, both of which showed a significant increase in PGP9.5 expression; moreover, when the TGF- $\beta 1$ overexpression vector was transfected and the TGF- $\beta 1$ inhibitor was added simultaneously, PGP9.5 expression was 

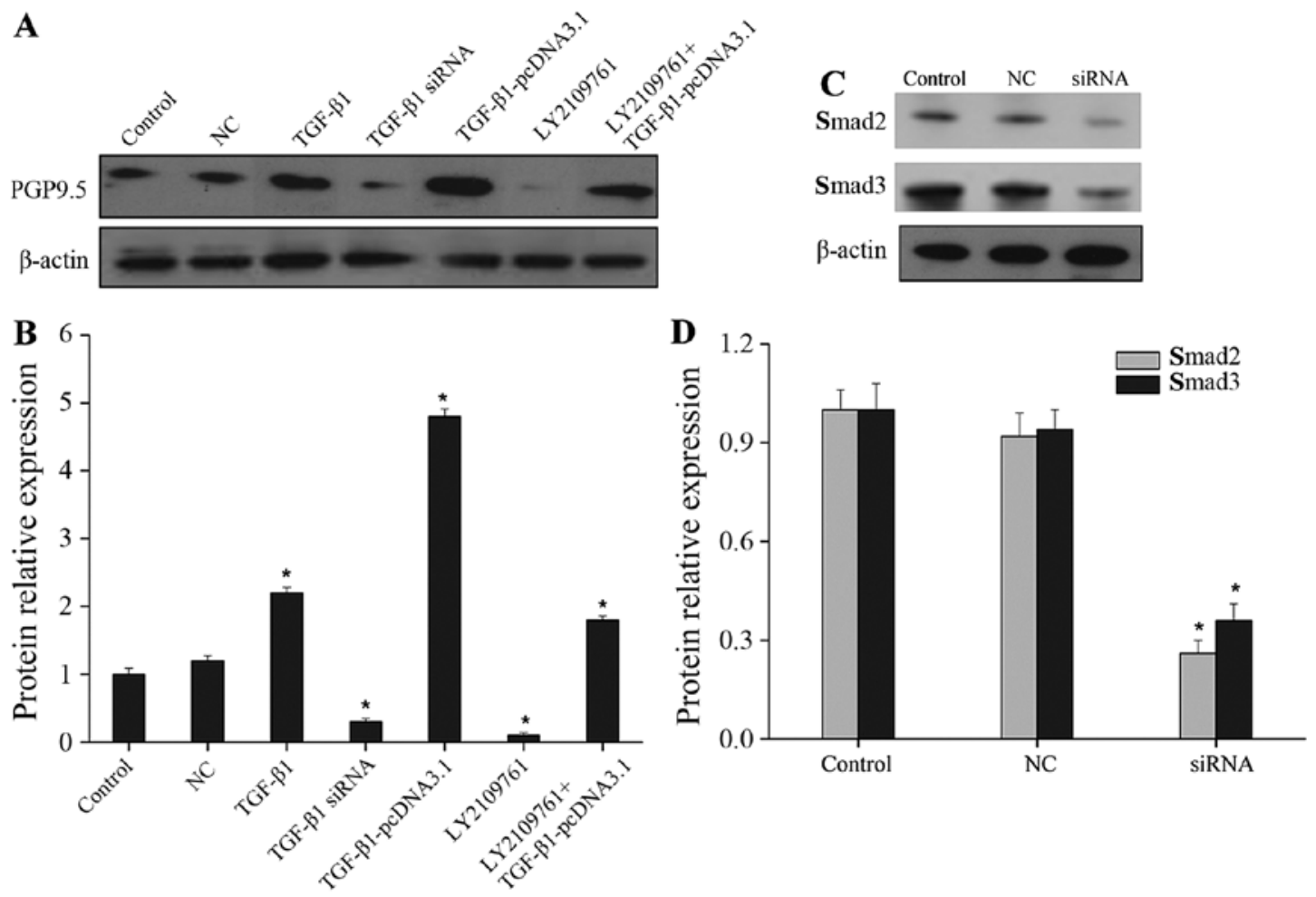

Figure 2. TGF- $\beta 1$ activates CAFs to express PGP9.5. (A and B) CAFs were transfected with TGF- $\beta 1$ siRNA or the TGF- $\beta 1$-pcDNA3.1 vector, then TGF- $\beta 1$ or LY2109761 was added or not and cultured for 48 h. PGP9.5 expression was examined by western blotting. (C and D) The inhibitory effects of Smad2 and Smad3 siRNAs were examined by western blotting. Data are means $\pm \mathrm{SD} ;{ }^{*} \mathrm{P}<0.01$ vs. the control.

markedly reduced when compared with the TGF- $\beta 1$ overexpression vector transfection group (Fig. 2A and B). In light of the above data, TGF- $\beta 1$ induced activation of CAFs in CRC and promoted PGP9.5 expression.

TGF- $\beta 1$ promotes PGP9.5 expression through Smad, ERK1/2 and PI3K pathways. Research was continued to investigate the pathway by which TGF- $\beta 1$ promotes PGP9.5 expression in CAFs. The classical TGF- $\beta$ signaling pathway is mediated by the Smad protein family mainly including Smad2/3 (21). The inhibitory effects of Smad2 and Smad3 siRNAs were first examined by western blotting (Fig. 2C and D). The effect of the Smad pathway on promotion of PGP9.5 expression by TGF- $\beta 1$ was then determined. As shown in Fig. $3 \mathrm{~A}$ and B, after the specific siRNA was used to downregulate $\operatorname{Smad} 2$ and Smad 3 expression, the promoting effect of TGF- $\beta 1$ on PGP9.5 expression was obviously decreased, suggesting that TGF- $\beta 1$ regulated PGP9.5 expression through the Smad pathway. In addition, TGF- $\beta$ was previously found to activate multiple intracellular signaling pathways, such as ERK1/2, PI3K/Akt, JNK and $\mathrm{p} 38$, to regulate the biological behaviors of cells (21). After TGF- $\beta 1$ and the specific inhibitors of the above mentioned pathways were added simultaneously, the expression of PGP9.5 was detected. The results indicated that after blocking the ERK $1 / 2$ and PI3K pathways, the promoting effect of TGF- $\beta 1$ on PGP9.5 expression was significantly suppressed; after blocking the JNK and p38 pathways, PGP9.5 expression displayed a less significant decrease than that of the TGF- $\beta 1$ group (Fig. $3 \mathrm{C}$ and D). Thus, in CRC CAFs, TGF- $\beta 1$ promoted PGP9.5 expression mainly through the Smad, ERK1/2 and PI3K pathways.
TGF- $\beta 1$ promotes CAF-induced PGP9.5 expression to increase the proliferation of CRC cells. TGF- $\beta 1$ can induce CAFs to express PGP9.5 which has been proven to play an important role in the occurrence and development of CRC (17-19). Further research was conducted to validate whether one of the mechanisms for promoting cancer cell growth by CAFs functioned through TGF- $\beta 1 /$ PGP9.5. CAFs and CRC cells were cultured on the upper and lower chambers of Transwell plates, respectively, thereby establishing a co-culture model. When TGF- $\beta 1$ was added to the CAFs, western blotting was used to determine PGP9.5 expression in the lower layer of CRC cells. According to the results, with the extension of the duration of TGF- $\beta 1$ induction, PGP9.5 expression was significantly enhanced in the media of the lower layer of CRC cells (Fig. 4A and B). Then BrdU assay showed a gradual and significant increase in the proliferation of CRC cells as the concentration of TGF- $\beta 1$ was increased (Fig. 4C). When TGF- $\beta 1$ was added into CAFs and the PGP9.5 inhibitor was added to the CRC cells concomitantly, the proliferation was increased compared with the control group, but the proliferation rate was obviously reduced compared with TGF- $\beta 1$ group (Fig. 4D). This suggests that PGP9.5 expressed by CAFs under the induction effect of TGF- $\beta 1$ can promote the proliferation of CRC cells. In contrast, when PGP9.5 was inhibited, the promoting effect of TGF- $\beta 1$-activated CAFs on CRC cells was obviously suppressed.

TGF- $\beta 1$ promotes CAF-induced PGP9.5 expression to suppress $C R C$ cell apoptosis. TGF- $\beta 1$ not only induced CAFs to express PGP9.5, thus promoting the proliferation of CRC cells, but may also affect other biological behaviors of the cells. 
A

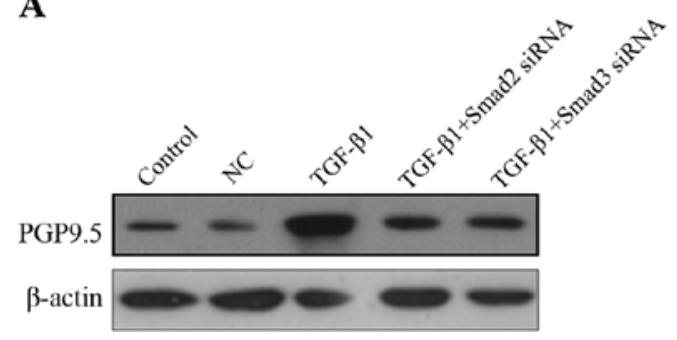

B

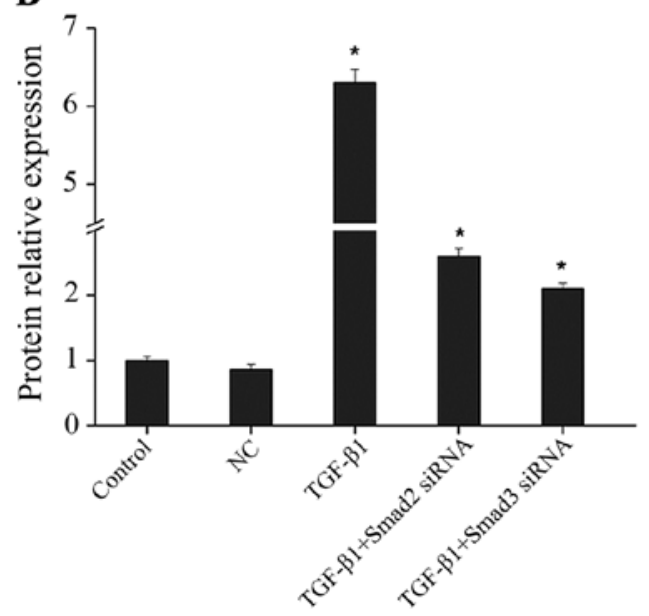

C
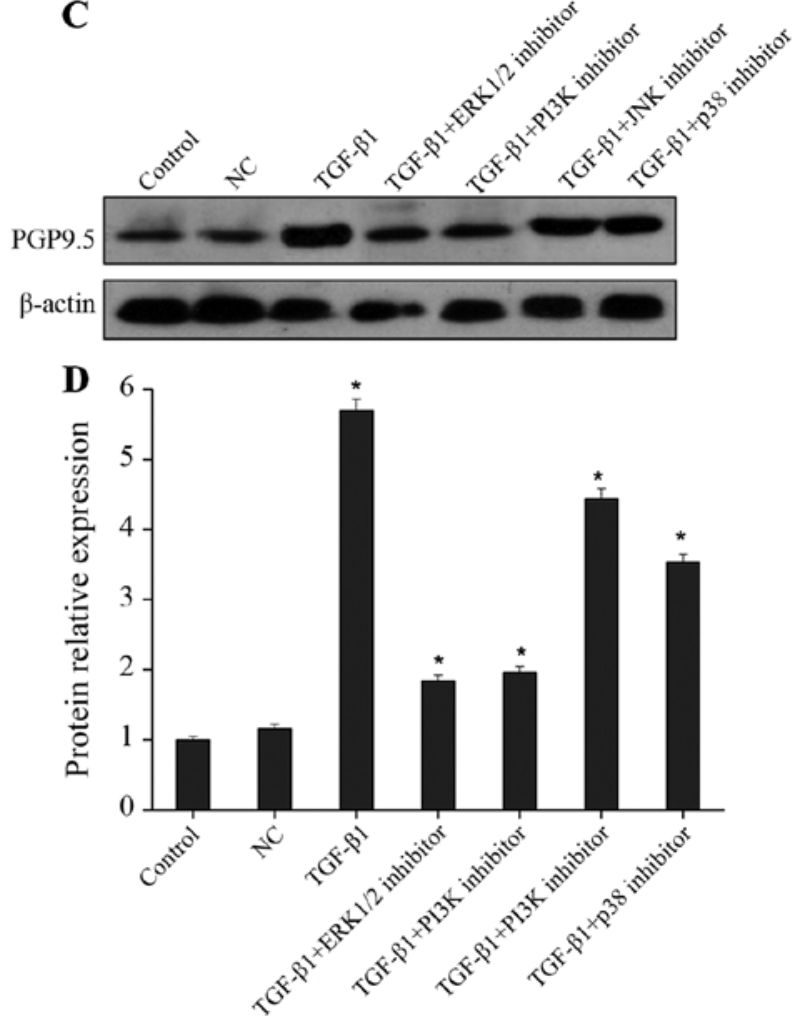

Figure 3. TGF- $\beta 1$ promotes PGP9.5 expression through Smad, ERK1/2 and PI3K pathways. (A and B) After Smad2 or Smad3 siRNA transfection and TGF- $\beta 1$ addition, CAFs were cultured for $48 \mathrm{~h}$ and PGP9.5 expression was examined by western blotting. (C and D) After TGF- $\beta 1$ addition, PD98059 (ERK1/2 inhibitor), LY294002 (PI3K inhibitor), SB203580 (p38 inhibitor) and SP600125 (JNK inhibitor) were added respectively, and then PGP9.5 expression was examined by western blotting. Results are presented as mean $(\mathrm{n}=3) \pm \mathrm{SD} ;{ }^{*} \mathrm{P}<0.01$ vs. the control.

$\mathbf{A}$

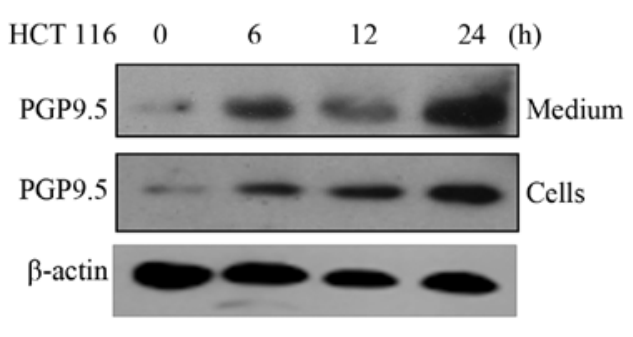

C

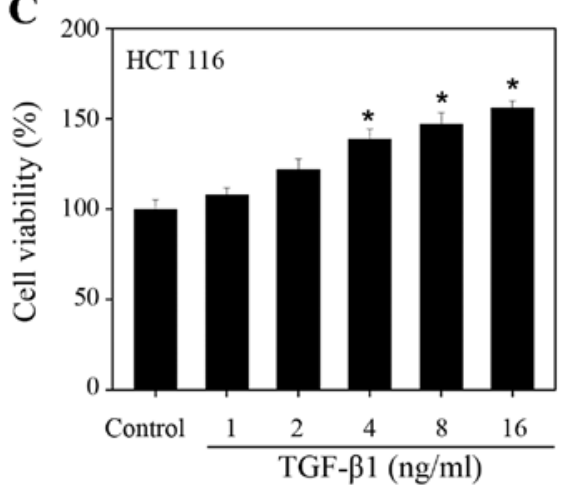

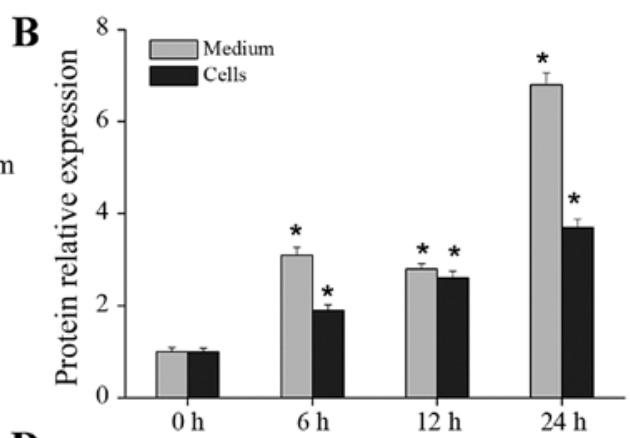

D

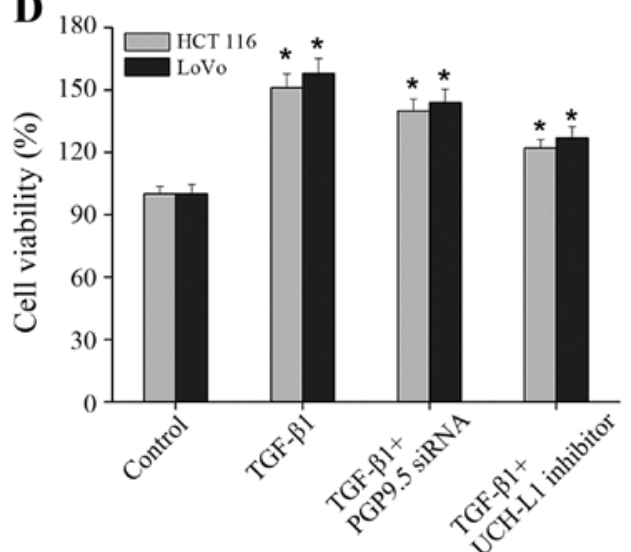

Figure 4. TGF- $\beta 1$ increases CAF-induced expression of PGP9.5 to promote the proliferation of colorectal cancer (CRC) cells. CAFs and CRC cells were cultured on the upper and lower chambers of Transwell plates, respectively. (A and B) When TGF- $\beta 1$ was added into the CAFs, western blotting was used to determine PGP9.5 expression in the lower layer of the CRC cells at different time points. (C) CAFs were treated with TGF- $\beta 1$ at different concentrations, and the cell proliferation of CRC cells was examined by BrdU assay. (D) When TGF- $\beta 1$ was added to the CAFs, the CRC cells were treated with PGP9.5 siRNA or the UCH-L1 (PGP9.5) inhibitor and cultured for $48 \mathrm{~h}$. The cell proliferation of the CRC cells was examined by BrdU assay. This experiment was repeated in triplicate with similar results; ${ }^{*} \mathrm{P}<0.01$. 

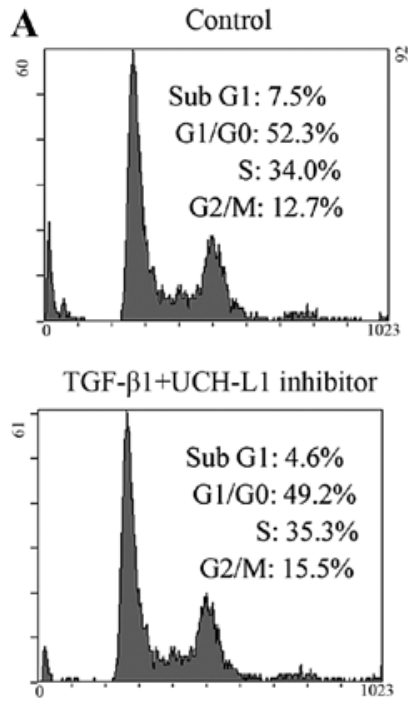
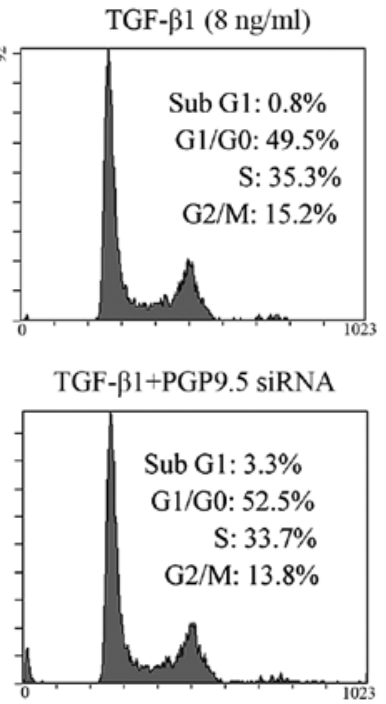

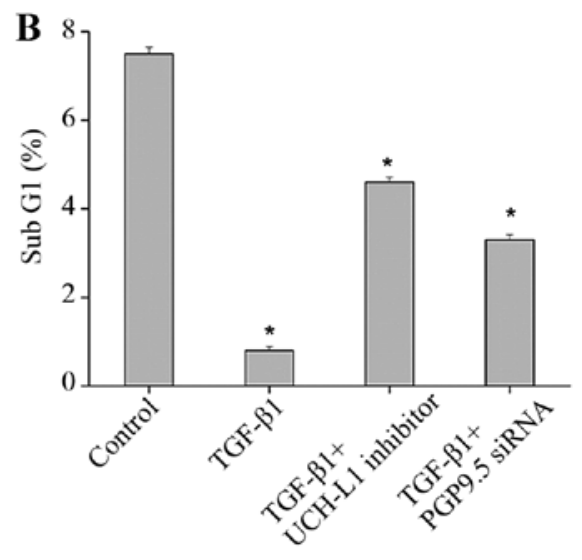

Figure 5. TGF- $\beta 1$ increases the CAF-induced expression of PGP9.5 to suppress colorectal cancer (CRC) cell apoptosis. CAFs and CRC cells were cultured on the upper and lower chambers of Transwell plates, respectively. When TGF- $\beta 1$ was added to the CAFs, the CRC cells were treated with PGP9.5 siRNA or UCH-L1 (PGP9.5) inhibitor and cultured for $48 \mathrm{~h}$. (A) Flow cytometry was used to detect cell cycle and apoptosis of the CRC cancer cells. (B) Quantitative analysis of Sub G1 cell percentage. Results are presented as mean $(n=3) \pm S D ;{ }^{*} \mathrm{P}<0.01$, vs. the control.

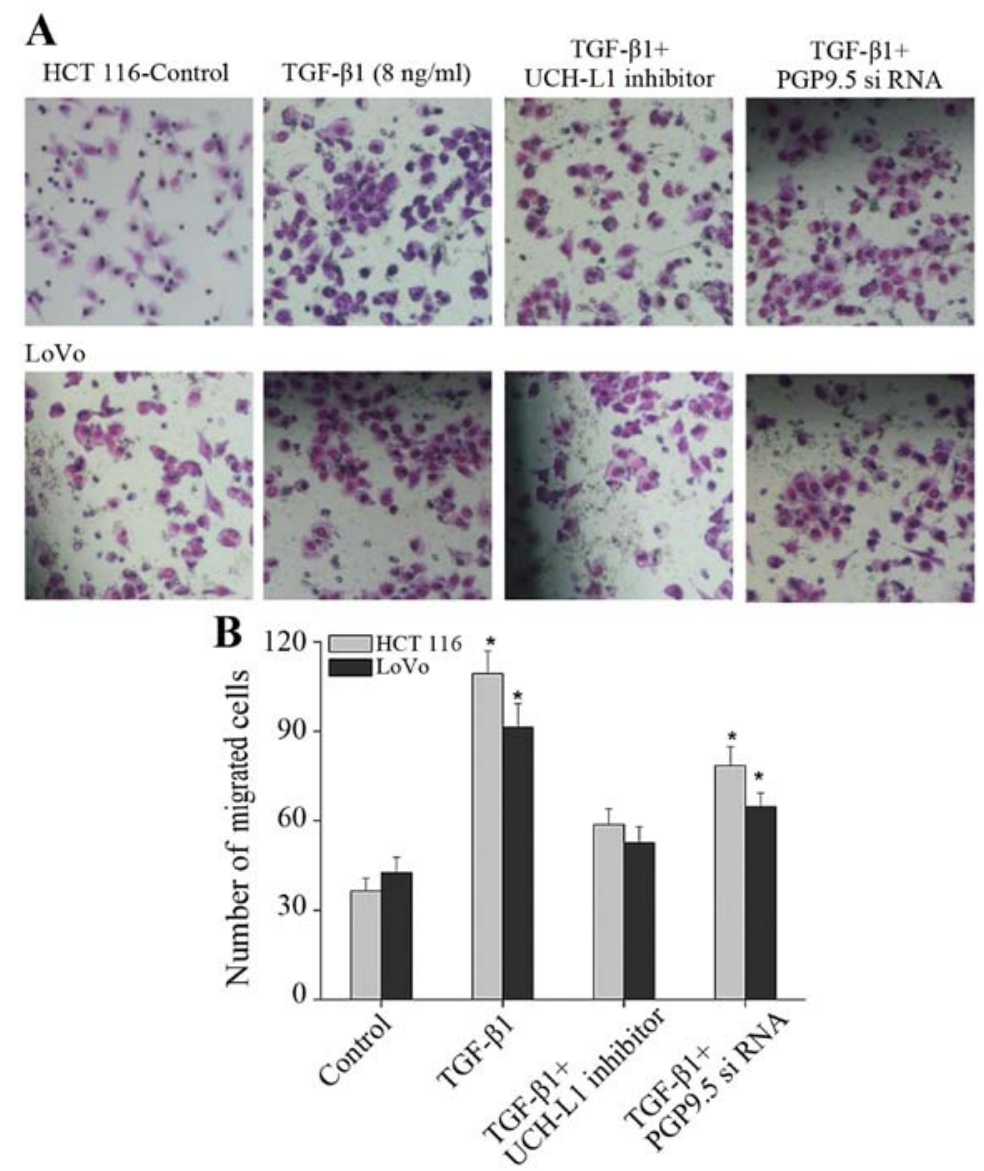

Figure 6. TGF- $\beta 1$ increases CAF-induced expression of PGP9.5 to promote the invasion of colorectal cancer (CRC) cells. CAFs and CRC cells were cultured on the upper and lower chambers of Transwell plates, respectively. When TGF- $\beta 1$ was added to the CAFs, the CRC cells were treated with PGP9.5 siRNA or the UCH-L1 (PGP9.5) inhibitor and cultured for $48 \mathrm{~h}$. (A) Invasion of the CRC cells was evaluated by Transwell Matrigel invasion assay. (B) Quantitative analysis of cell invasion. Each bar represents mean \pm SD from 3 samples; ${ }^{*} \mathrm{P}<0.01$, vs. the control.

Therefore, flow cytometry was used to assess the cell cycle and apoptosis. The results indicated that when TGF- $\beta 1$ was added into the CAFs, the proportion of the apoptosis peak (Sub
G1 peak) of CRC cells was significantly reduced (Fig. 5). When the TGF- $\beta 1$ inhibitor was added to the CRC cells, the proportion of the Sub G1 peak was also decreased, but was higher than 
that of the TGF- $\beta 1$ alone group (Fig. 5). From the above data, we concluded that addition of the TGF- $\beta 1$ inhibitor alone into tumor cells cannot completely block the effect of TGF- $\beta 1$ activated CAFs on tumor cells. Similarly, after the PGP9.5 inhibitor was added to the CRC cells, the proportion of Sub G1 peak also declined compared with the control group, but was still higher than that of the TGF- $\beta 1$ alone group (Fig. 5). This suggested that PGP9.5 plays a role in the inhibitory process of TGF- $\beta 1$-activated CAFs against CRC cell apoptosis; however, the effect of TGF- $\beta 1$-activated CAFs against tumor cells was not completely blocked by inhibiting the function of PGP9.5 and may also secrete other factors to play a role.

TGF- $\beta 1$ promotes CAF-induced PGP9.5 expression to promote the invasion of $C R C$ cells. One significant effect of activated CAFs on tumor cells is to promote invasion and metastasis. Thus, Transwell assay was applied to detect the effect of PGP9.5 expressed by CAFs under the induction effect of TGF- $\beta 1$. After TGF- $\beta 1$ was added into CAFs, the invasion ability of CRC cells was significantly increased (Fig. 6). When CAFs and the UCH-LI (PGP9.5) inhibitor was added into CAFs and CRC cells, respectively, however, the invasion ability of the cells increased compared with the control group, but was obviously suppressed when compared with the TGF- $\beta 1$ alone group (Fig. 6). Thus, after CAFs were activated by TGF- $\beta 1$, the invasion of tumor cells was significantly promoted, in which PGP9.5 has a key function as inhibition of the PGP9.5 effect blocked the promotion of TGF- $\beta 1$-activiated CAFs on the invasion of CRC cells to some extent.

\section{Discussion}

Using cancer-associated fibroblasts (CAFs) for diagnosis and antitumor treatment for colorectal cancer (CRC) has just begun. The in-depth research of CAFs may help to elucidate the mechanism of tumorigenesis and tumor progression, providing new specific markers for early diagnosis of tumors and new targets for tumor treatment $(2,3)$. Currently, although there has been some progress in investigating the relationship between CAFs and CRC development, there are still many issues which remain unsolved.

CRC cells secrete growth factors [e.g., transforming growth factor (TGF) $-\beta$ and IGF], promoting the acccumulation and activation of fibroblasts involved in cancer cell proliferation, metastasis and other pathophysiological processes (6). Sappino et al (22) reported that CRC cells release TGF- $\beta$ to induce mesenchymal reaction and prompt CAF activation, while CAFs secreted various growth factors, collagens and proteases, which affect the tumor cells themselves in turn. The present study further demonstrated that TGF- $\beta 1$ can promote activation of CAFs, and the activiation marker $\alpha$-SMA expression increased markedly. In normal colon epithelial cells and early colon cancer, TGF- $\beta$ mainly inhibits cell proliferation, while in advanced colon cancer, it promotes the invasion and metastasis of tumor cells by inducing epithelial-mesenchymal transition (EMT). There have been many studies to support the promotion of TGF- $\beta$-activated CAFs on the growth of tumor cells (23).

The present study further found that TGF- $\beta 1$ can promote CAFs to overexpress PGP9.5 through the classical Smad,
ERK1/2 and PI3K pathways, in which JNK and p38 pathways were not obvious. The relationship between PGP9.5 and tumors has been reported in recent years $(15,16)$. A large number of clinical studies have shown that a high level of PGP9.5 in breast cancer, CRC, pancreatic cancer, and other tumors is closely associated with a lower survival rate $(17,24,25)$. The carcinogenesis of PGP9.5 has been reported in non-small cell lung cancer and colon cancer $(25,26)$. According to previous studies, PGP9.5 enhanced the activity of CDKs in tumor cells (27), promoted cell survival by activating the Akt signaling pathway (28), and accelerated the metastasis of tumor cells by activating the Wnt signaling pathway (29). Although PGP9.5 has been reported to be a cancer-suppressor gene (30), the findings concerning its role in CRC are consistent at present. PGP9.5 was shown to play an important role in the progression of CRC, which may be an independent prognostic factor $(19,24,25)$. Mizukami et al (19) indicated that PGP9.5 was less frequently methylated in metastatic CRC, suggesting that PGP9.5 hypomethylation may play an important role in reexpression of the PGP9.5 gene in CRC. Thereby, routine test of its expression in CRC contributes to evaluation of diagnosis and prognosis of CRC. Akishima-Fukasawa et al (25) also found that PGP9.5 expression in cultured normal fibroblasts was increased by TGF- $\beta$ stimulation, indicating the phenotypic alteration to activated fibroblast. Thus, PGP9.5 overexpression induced by CAFs under the induction effect of TGF- $\beta 1$ may play a key role in CRC.

The further research results indicated that the proliferation and invasion of CRC cells were promoted when CAFs were activated by TGF- $\beta 1$ while their apoptosis was inhibited. This was also achieved by promoting PGP9.5 expression. Nevertheless, the effect of TGF- $\beta 1$-activiated CAFs against tumor cells was not completely blocked when the function of PGP9.5 was inhibited. Based on the above data, PGP9.5 played an important role in the process of CAF activation by TGF- $\beta 1$ and promotion of cancer cell growth, but TGF- $\beta 1$ activated CAFs may secrete other factors that also play a role. Hawinkels et al (8) also found that the interaction of tumor cells with resident fibroblasts results in hyperactivated TGF- $\beta 1$ signaling and subsequent transdifferentiation of the fibroblasts into $\alpha$-SMA-positive CAFs. In turn this leads to cumulative production of TGF- $\beta$ and proteinases within the tumor microenvironment, creating a cancer-promoting feedback loop. Gonzalez-Zubeldia et al (31) showed that TGF $\beta 1$ promoted co-travelling of CRC cells and CAFs to the liver to enhance metastasis. Activation of the TGF- $\beta$ pathway in cancer cells did not influence tumor growth, but cancer cell-derived-TGF- $\beta$ ligands affected stromal cells in a paracrine manner, leading to fibroblast activation and enhanced tumor growth (32). Functional evaluations in coculture experiments showed that TGF- $\beta$ enhanced the aggressiveness of ovarian cancer cells by upregulating VCAN in CAFs (33). CAFs were measurably different from normal fibroblasts in response to TGF- $\beta 1$, suggesting that TGF- $\beta$ stimulates changes in CAFs that foster tumor invasion (11). Therefore, TGF- $\beta 1$ can promote CAFs to express a variety of factors such as PGP9.5, thus acting on cancer cells and promoting the growth of cancer cells.

These findings of CAFs help to elucidate the mechanism of tumorigenesis and tumor progression, suggesting new specific markers for early diagnosis of tumors and new targets for 
tumor treatment. Nevertheless, further in-depth research is needed to investigate the mechanisms.

\section{References}

1. Siegel RL, Miller KD and Jemal A: Cancer statistics, 2015. CA Cancer J Clin 65: 5-29, 2015.

2. Joyce JA and Pollard JW: Microenvironmental regulation of metastasis. Nat Rev Cancer 9: 239-252, 2009.

3. Hanahan D and Coussens LM: Accessories to the crime: Functions of cells recruited to the tumor microenvironment. Cancer Cell 21: 309-322, 2012.

4. Tommelein J, Verset L, Boterberg T, Demetter P, Bracke M and De Wever O: Cancer-associated fibroblasts connect metastasis-promoting communication in colorectal cancer. Front Oncol 5: 63, 2015.

5. Denys H, Derycke L, Hendrix A, Westbroek W, Gheldof A, Narine K, Pauwels P, Gespach C, Bracke M and De Wever O Differential impact of TGF-beta and EGF on fibroblast differentiation and invasion reciprocally promotes colon cancer cell invasion. Cancer Lett 266: 263-274, 2008.

6. Mishra P, Banerjee D and Ben-Baruch A: Chemokines at the crossroads of tumor-fibroblast interactions that promote malignancy. J Leukoc Biol 89: 31-39, 2011.

7. Calon A, Espinet E, Palomo-Ponce S, Tauriello DV, Iglesias M, Céspedes MV, Sevillano M, Nadal C, Jung P, Zhang XH, et al: Dependency of colorectal cancer on a TGF- $\beta$-driven program in stromal cells for metastasis initiation. Cancer Cell 22: 571-584, 2012.

8. Hawinkels LJ, Paauwe M, Verspaget HW, Wiercinska E, van der Zon JM, van der Ploeg K, Koelink PJ, Lindeman JH, Mesker W, ten Dijke P, et al: Interaction with colon cancer cells hyperactivates TGF- $\beta$ signaling in cancer-associated fibroblasts. Oncogene 33: 97-107, 2014

9. Taguchi A, Kawana K, Tomio K, Yamashita A, Isobe $\mathrm{Y}$, Nagasaka K, Koga K, Inoue T, Nishida H, Kojima S, et al: Matrix metalloproteinase (MMP)-9 in cancer-associated fibroblasts (CAFs) is suppressed by omega-3 polyunsaturated fatty acids in vitro and in vivo. PLoS One 9: e89605, 2014

10. Brentnall TA: Arousal of cancer-associated stromal fibroblasts: Palladin-activated fibroblasts promote tumor invasion. Cell Adhes Migr 6: 488-494, 2012.

11. Casey TM, Eneman J, Crocker A, White J, Tessitore J, Stanley M, Harlow S, Bunn JY, Weaver D, Muss H, et al: Cancer associated fibroblasts stimulated by transforming growth factor betal (TGF-beta 1) increase invasion rate of tumor cells: A population study. Breast Cancer Res Treat 110: 39-49, 2008.

12. Dawes LJ, Eldred JA, Anderson IK, Sleeman M, Reddan JR, Duncan G and Wormstone IM: TGF beta-induced contraction is not promoted by fibronectin-fibronectin receptor interaction, or alpha SMA expression. Invest Ophthalmol Vis Sci 49: 650-661, 2008.

13. Kuperwasser C, Chavarria T, Wu M, Magrane G, Gray JW, Carey L, Richardson A and Weinberg RA: Reconstruction of functionally normal and malignant human breast tissues in mice. Proc Natl Acad Sci USA 101: 4966-4971, 2004.

14. Ao M, Williams K, Bhowmick NA and Hayward SW: Transforming growth factor-beta promotes invasion in tumorigenic but not in nontumorigenic human prostatic epithelial cells. Cancer Res 66: 8007-8016, 2006.

15. Mandelker DL, Yamashita K, Tokumaru Y, Mimori K, Howard DL, Tanaka Y, Carvalho AL, Jiang WW, Park HL, Kim MS, et al: PGP9.5 promoter methylation is an independent prognostic factor for esophageal squamous cell carcinoma. Cancer Res 65: 4963-4968, 2005.

16. Lee YM, Lee JY, Kim MJ, Bae HI, Park JY, Kim SG and Kim DS: Hypomethylation of the protein gene product 9.5 promoter region in gallbladder cancer and its relationship with clinicopathological features. Cancer Sci 97: 1205-1210, 2006.

17. Ohta T and Fukuda M: Ubiquitin and breast cancer. Oncogene 23: 2079-2088, 2004.
18. Watanabe T, Kobunai T, Toda E, Kanazawa T, Kazama Y, Tanaka J, Tanaka T, Yamamoto Y, Hata K, Kojima T, et al: Gene expression signature and the prediction of ulcerative colitis-associated colorectal cancer by DNA microarray. Clin Cancer Res 13: 415-420, 2007.

19. Mizukami H, Shirahata A, Goto T, Sakata M, Saito M, Ishibashi K, Kigawa G, Nemoto H, Sanada Y and Hibi K: PGP9.5 methylation as a marker for metastatic colorectal cancer. Anticancer Res 28: 2697-2700, 2008.

20. Nakagawa H, Liyanarachchi S, Davuluri RV, Auer H, Martin EW Jr, de la Chapelle A and Frankel WL: Role of cancerassociated stromal fibroblasts in metastatic colon cancer to the liver and their expression profiles. Oncogene 23: 7366-7377, 2004.

21. Derynck R and Zhang YE: Smad-dependent and Smadindependent pathways in TGF-beta family signalling. Nature 425: 577-584, 2003

22. Sappino AP, Schürch W and Gabbiani G: Differentiation repertoire of fibroblastic cells: Expression of cytoskeletal proteins as marker of phenotypic modulations. Lab Invest 63: 144-161, 1990.

23. Calon A, Tauriello DV and Batlle E: TGF-beta in CAF-mediated tumor growth and metastasis. Semin Cancer Biol 25: 15-22, 2014.

24. Yamazaki T, Hibi K, Takase T, Tezel E, Nakayama H, Kasai Y, Ito K, Akiyama S, Nagasaka T and Nakao A: PGP9.5 as a marker for invasive colorectal cancer. Clin Cancer Res 8: 192-195, 2002.

25. Akishima-Fukasawa $Y$, Ino Y, Nakanishi Y, Miura A, Moriya Y, Kondo T, Kanai Y and Hirohashi S: Significance of PGP9.5 expression in cancer-associated fibroblasts for prognosis of colorectal carcinoma. Am J Clin Pathol 134: 71-79, 2010.

26. Kim HJ, Kim YM, Lim S, Nam YK, Jeong J, Kim HJ and Lee KJ: Ubiquitin C-terminal hydrolase-L1 is a key regulator of tumor cell invasion and metastasis. Oncogene 28: 117-127, 2009.

27. Kabuta T, Mitsui T, Takahashi M, Fujiwara Y, Kabuta C, Konya C, Tsuchiya Y, Hatanaka Y, Uchida K, Hohjoh H, et al: Ubiquitin C-terminal hydrolase L1 (UCH-L1) acts as a novel potentiator of cyclin-dependent kinases to enhance cell proliferation independently of its hydrolase activity. J Biol Chem 288: 12615-12626, 2013.

28. Hussain S, Foreman O, Perkins SL, Witzig TE, Miles RR, van Deursen J and Galardy PJ: The de-ubiquitinase UCH-L1 is an oncogene that drives the development of lymphoma in vivo by deregulating PHLPP1 and Akt signaling. Leukemia 24: 1641-1655, 2010

29. Bheda A, Yue W, Gullapalli A, Whitehurst C, Liu R, Pagano JS and Shackelford J: Positive reciprocal regulation of ubiquitin C-terminal hydrolase L1 and beta-catenin/TCF signaling. PLoS One 4: e5955, 2009

30. Yu J, Tao Q, Cheung KF, Jin H, Poon FF, Wang X, Li H, Cheng YY, Röcken C, Ebert MP, et al: Epigenetic identification of ubiquitin carboxyl-terminal hydrolase $\mathrm{L} 1$ as a functional tumor suppressor and biomarker for hepatocellular carcinoma and other digestive tumors. Hepatology 48: 508-518, 2008.

31. Gonzalez-Zubeldia I, Dotor J, Redrado M, Bleau AM, Manrique I, de Aberasturi AL, Villalba $M$ and Calvo A: Co-migration of colon cancer cells and CAFs induced by TGF $\beta_{1}$ enhances liver metastasis. Cell Tissue Res 359: 829-839, 2015.

32. Guido C, Whitaker-Menezes D, Capparelli C, Balliet R, Lin Z, Pestell RG, Howell A, Aquila S, Andò S, Martinez-Outschoorn U, et al: Metabolic reprogramming of cancer-associated fibroblasts by TGF- $\beta$ drives tumor growth: Connecting TGF- $\beta$ signaling with 'Warburg-like' cancer metabolism and L-lactate production. Cell Cycle 11: 3019-3035, 2012.

33. Yeung TL, Leung CS, Wong KK, Samimi G, Thompson MS, Liu J, Zaid TM, Ghosh S, Birrer MJ and Mok SC: TGF- $\beta$ modulates ovarian cancer invasion by upregulating CAF-derived versican in the tumor microenvironment. Cancer Res 73: 5016-5028, 2013 